\title{
Air change rate vs airflow pathway: bioaerosol containment and removal in patient rooms
}

\author{
K Grosskopf \\ From 3rd International Conference on Prevention and Infection Control (ICPIC 2015) \\ Geneva, Switzerland. 16-19 June 2015
}

\section{Introduction}

Recent studies have shown that higher air change rates may have the unintended consequence of creating turbulent airflows that entrain high concentrations of infectious particles within the breathing zone, and possibly, breakdown pressure relationships necessary to contain the spread of infectious particles to other clinical spaces.

\section{Objectives}

A series of experimental and numerical tests were conducted in an actual hospital to observe the containment and removal of respirable aerosols $(0.5-10 \mu \mathrm{m})$ with respect to ventilation rate and directional airflow in a general patient room, and, an airborne infectious isolation room (AIIR).

\section{Methods}

A total of four experimental tests were conducted; two each in a general patient room and an infectious isolation room. A synthetic oil (polyaliphatic olefin) was continuously aerosolized at a rate of $15 \mathrm{mg} / 0.4 \mathrm{~L}$ of air per second to generate an aerosol $(0.5 \mu \mathrm{m}-10 \mu \mathrm{m})$ at the approximate height of a patient lying at rest $(0.8 \mathrm{~m})$. Particle size distribution samples were drawn at $30 \mathrm{sec}$ intervals at 30 sampling locations in the test rooms over 4 hours. Computational analyses were used to validate the experimental results, and, to further quantify the particle transport phenomena.

\section{Results}

Increasing mechanical ventilation from 2.5 to $5.5 \mathrm{ACH}$ reduced aerosol concentrations only $30 \%$ on average. However, particle concentrations were more than $40 \%$ higher in pathways between the source and exhaust as was the suspension and migration of larger particles $(3-10 \mu \mathrm{m})$ throughout the patient room(s). Higher ventilation rates

Engineering, University of Nebraska, Lincoln, NE, USA did not appear to affect directional airflow relationships between corridors and patient rooms having anterooms and a pressure differential of $\geq 2.5 \mathrm{~Pa}$.

\section{Conclusion}

Higher ventilation rates were not found to be proportionately effective in reducing aerosol concentrations. Airflow pathways, not air change rates, were found to be the dominant environmental factor for bioaerosol migration and potential cross-infection.

\section{Disclosure of interest}

None declared.

\section{Published: 16 June 2015}

References

1. Grosskopf K, Mousavi E: Ventilation and Transport Bioaerosols in HealthCare Environments. ASHRAE Journal 2014, 56.8:22.

2. Memarzadeh $F, X u$ W: Role of air changes per hour $(A C H)$ in possible transmission of airborne infections. Building Simulation 2012, 5(1):15-28.

doi:10.1186/2047-2994-4-S1-P94

Cite this article as: Grosskopf: Air change rate vs airflow pathway: bioaerosol containment and removal in patient rooms. Antimicrobial Resistance and Infection Control 2015 4(Suppl 1):P94.

Submit your next manuscript to BioMed Central and take full advantage of:

- Convenient online submission

- Thorough peer review

- No space constraints or color figure charges

- Immediate publication on acceptance

- Inclusion in PubMed, CAS, Scopus and Google Scholar

- Research which is freely available for redistribution 